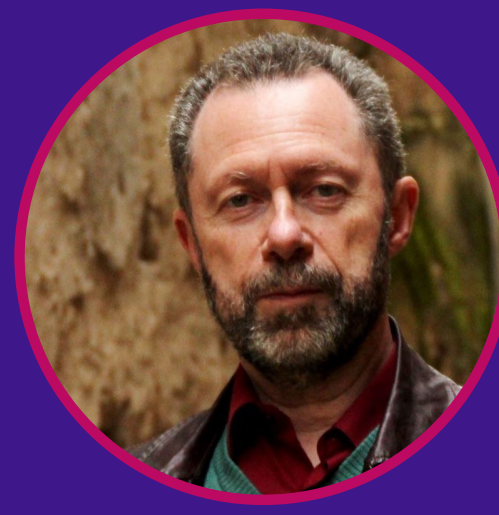

\title{
Las estrategias de campaña 'online' de los partidos y candidatos políticos
}

\author{
Party and candidate online political campaign strategies
}

\author{
Dr. José Luis Dader \\ Universidad Complutense de Madrid \\ dader@ccinf.ucm.es
}

Recibido: 8 de mayo de 2018.

Received: May 8th 2018.

Aceptado: 5 de junio de 2018.

Accepted: June 5th 2018.

(C) $(1) \ominus$ Esta obra está bajo una licencia internacional Creative
Commons Atribución-NoComercial-SinDerivadas 4.0.

DOI: https://doi.org/10.21555/rpc.voi1.2299

Cómo citar: Dader, J. L. (2019). Las estrategias de campaña 'online' de los partidos y candidatos políticos. RPC, 1(1), 26-40. https://doi.org/10.21555/rpc.v0i1.2299

Revista Panamericana de Comunicación, Año 1, N. 1, enero-diciembre 2019, pp. 26-40.

\section{RESUMEN}

El activismo digital y la analítica de datos aplicados en las elecciones presidenciales estadounidenses de 2008, 2012 y 2016 han consolidado la "gestión computacional de campañas" como un recurso estratégico que implica un cambio de paradigma en la concepción de la comunicación política electoral. La incorporación de esas mismas herramientas y prácticas de movilización y búsqueda del voto a los comicios nacionales españoles de 2015 y 2016 demuestra que la campaña 'online' también adquiere un rol creciente en otras democracias de desarrollo tecnopolítico todavía menor. Los principales cambios del nuevo paradigma son: la microsegmentación y geolocalización de sectores muy particularizados de electores para el posterior envío de mensajes ajusta- dos a cada microperfil, el papel decisivo de los simpatizantes como intermediarios del contacto electoral en una "influencia en dos pasos digital" y la generación por los grupos políticos de un discurso llamativo para las redes sociales con el objetivo de esquivar su dependencia ante los hegemónicos medios de comunicación de masas. Entre las transformación más profundas que se perciben se identifica el "tecnocabildeo", o práctica del clientelismo propio de los pequeños grupos, las comunidades primitivas y el siglo XIX, a través de herramientas del siglo XXI.

Palabras-clave: Comunicación política, ciberpolítica, campañas 'online', gestión computacional de campañas. 


\section{ABSTRACT}

Digital activism and data analytics applied to the US Presidential elections of 2008, 2012 and 2016 helped consolidate "computational campaign management" as a strategic resource that implied a change of paradigm in our understanding of political communication during electoral campaigns. The use of the same tools and practices of political and electoral mobilization in the Spanish 2015 and 2016 elections proves that online campaigns are also becoming increasingly important in other less technologically developed democracies. The main changes brought about by the new paradigm are as follows. Firstly, the micro-segmentation and geo-localization of voters into very specific sectors that are then targeted messages tailored to their profiles. Sec- ondly, the decisive role played by party supporters as intermediaries between parties and other voters, using their influence online. Moreover, the use of social media by political groups in order to generate an attractive discourse that will bypass those of otherwise hegemonic mass media. Among these significant transformations we can also identify technological forms of lobbying in small groups and primitive communities which somewhat mirror 19th century practices, while using 21st century technology.

Key Words: Political communication, cyberpolitics, online electoral campaigns, computational electoral campaign management
L a actividad digital en campañas electorales comenzó a mediados de los años noventa del siglo pasado como un adorno vanguardista del que no se esperaba una influencia excesiva sobre la dinámica política y menos aún sobre las intenciones de voto. La batalla se libraba -y se suponía que se seguiría librando-, por los apoyos de los grandes medios de masas -sobre todo la televisión-, en el despliegue de la publicidad electoral ante todo de la radiotelevisiva-, y mediante la seducción de las grandes audiencias y de los analistas mediáticos en los debates televisados o las entrevistas de los candidatos más destacados. Aun así, a la altura de 1999, un académico visionario llegó a escribir que "esta nueva tecnología no revolucionará el resultado electoral pero sí cambiará la forma de hacer campañas" (Richard Davis, 1999:120).

Pocos candidatos o partidos consideraron al pie de la letra el vaticinio, a pesar de que ya en las primarias y presidenciales estadounidenses del año 2000 se hizo evidente el auge de los sitios webs y los blogs de los principales contendientes. Una considerable cantidad de electores seguía dichas páginas, aportaba comentarios y también donativos por vía telemática o utilizaba sus cuentas de correo para redistribuir mensajes relacionados con la campaña. Pero casi veinte años más tarde, no sólo las estrategias y logística electoral se han adaptado de manera intensiva al entorno digital, sino que la propia decantación del voto comienza a asociarse en una importante medida con las nuevas formas de análisis, contacto y elaboración del discurso que facilita la ciberpolítica (Hill y Hughes, 1998; LaPotin, 2008; Martins, 2013; Cotarelo, 2013; Cotarelo y Gil, 2017). Un proyecto de investigación que he tenido la satisfacción de dirigir sobre las campañas digitales en los procesos electorales españoles de 2015 y 2016 nos ha permitido contrastar el caso local con la evolución internacional que van adoptando las campañas 'online' y nos permite hacer balance del grado de transformación que la co- 
municación electoral en la Era de Internet ha alcanzado ya y amenaza con desarrollar todavía más (Dader y Campos, 2017).

La experiencia vivida en Estados Unidos, tras las sucesivas carreras presidenciales de Obama (2008 y 2012) y Trump (2016) -sin olvidar tampoco la actividad de sus competidores derrotados-, descubre un fenómeno, desarrollado también en muchos otros países en menor medida, que cabe sintetizar en las siguientes claves: 1) Configuración de una infraestructura de investigación de grandes masas de datos ("Big Data") mediante minería ciberestadística, destinada a lograr la geolocalización y microsegmentación del mayor número posible de bolsas dispersas pero identificables del electorado, 2) Planificación estratégica y coordinación digital de la información obtenida en el entorno anterior para usarla como herramienta de ciberactivismo digital, 3) Organización de redes de colaboradores y militantes para acciones de apoyo en ejecución, diseminación y escucha digital, 4) Aplicación estratégica de una concepción integral de las campañas: Las actividades 'offline' han de estar coordinadas y respaldadas con la investigación y la actividad 'online', y 5) Producción de un ciberdiscurso especialmente adaptado a la comunicación "persona-a-persona" o viral (Núñez, 2011), al mismo tiempo que altamente reactivo o descollante para las terminales mediáticas tradicionales.

\section{EL SALTO DIGITAL DE LAS CAMPAÑAS DE OBAMA}

Aun sin mostrar el grado de extensión e intensidad que estas intervenciones han ido alcanzando después, ya la primera campaña de Obama se articuló en torno a esos cinco ejes. Como describe el pormenorizado estudio de Kreiss (2012), observador participante en aquel despliegue, la implantación de dicho sistema se fraguó a lo largo de una dilatada planificación y puesta en marcha. Poco después de la derrota de los demócratas en 2004 y hasta llegar a 2007, una restructuración interna de la dirección nacional del partido, encabezada por su nuevo presidente, Howard Dean, había ido configurando parsimoniosamente, con la participación de diversas empresas de minería de datos, una red digital de ficheros elec- torales de cobertura federal denominada Vote Builder. El sistema dispuso de una interfaz de acceso al Registro Nacional de Votantes conectada también con la plataforma de campaña demócrata Party Builder, para recopilación, intercambio y actualización de perfiles informatizados de grandes masas de ciudadanos. El sistema pudo ser explotado también por los equipos de otros candidatos. Pero fue el de Obama el que, mediante la incorporación entusiasta de grandes contingentes de voluntarios y la contratación de expertos procedentes de esa incipiente industria de la minería de datos electorales, integró el sistema anterior con la información generada por la red de blogs y cuentas de simpatizantes de la plataforma $M y B o$, mediante otra interfaz de conexión propia, $N 2 N$. Los equipos que trabajaban en la campaña podían acceder así a esa interfaz para aprovechar sus datos, actualizarlos con sus propias averiguaciones, y planificar las llamadas telefónicas, visitas a hogares, etc. Nunca antes una campaña había relacionado semejante envergadura de información digitalizada ni la había aprovechado con intensidad equiparable para coordinar las actividades comunitarias de centenares de miles de activistas y grupos a lo largo de toda la geografía, con una capilaridad extendida hasta el nivel barrial. Los "grassroots" o comunidades de base nunca habían desaparecido de la actividad electoral estadounidense, pero en la era de la comunicación de masas y el protagonismo de los grandes medios, llevaban décadas de consideración estratégica secundaria. Ahora, con la instauración de lo que se empezaba a llamar la gestión computacional de campañas ("computational management style", "networked electoral campaigning"; cfr. Kreiss, 2012: 6, 188, 193, entre otras menciones), se producía la recapitalización de la comunicación electoral a pie de calle, a partir de los grupos de simpatizantes. Volvía así al centro del márketing político un estilo de campaña del siglo XIX renovado mediante las herramientas del siglo XXI (Vaccari, 2010).

Todo ese sistema fue perfeccionado para el proceso de reelección de Obama en 2011-12 hasta lograr una 'integración total'. Y prueba de su mayor eficacia fue el propio resultado en las urnas: Si en 2008, el carisma y frescura discursiva del candidato, unido al cansancio ante los gobiernos republicanos, habían 
desencadenado 'la tormenta perfecta' en favor del líder del 'yes, we can', ${ }^{1}$, en 2012, el desgaste de aquel movimiento y el menor desequilibrio en el tratamiento mediático de los dos rivales mantuvo un ambiente de gran incertidumbre hasta el final y arrojó un resultado poco distanciado en el reparto global de los votos populares (51,0\% frente a $47,3 \%)$. Sin embargo, esa aparente igualdad quedó completamente desmantelada en el terreno donde institucionalmente se determina la presidencia: 332 delegados obtenidos por Obama frente a los 206 logrados por Romney. Una abrumadora distancia que, conforme al sistema mayoritario de reparto por estados, se fraguó en pequeñas diferencias territoriales sabiamente conquistadas mediante la sincronización de movilizaciones e intervención decisiva en los puntos neurálgicos, a partir de la gestión computacional de ingentes masas de datos. Algo muy parecido a lo que, de forma aún más radical -y sorpresiva para las viejas mentalidades del sistema mediático-, se viviría cuatro años más tarde en favor de Donald Trump.

Un componente esencial de la perfeccionada maquinaria digital de Obama en 2012 fue la creación de la plataforma "Dashboard", en la que cientos de miles de voluntarios de campaña incorporaban los datos de la actividad que cada simpatizante individual realizaba en su entorno más cercano (Ilamadas telefónicas a conocidos o vecinos, mensajes de petición de donativos, visitas domiciliarias...). El registro de toda esa labor y la evaluación de sus resultados eran centralizados en el sistema informático The Cave, para el que trabajaron en su fase final unos 120 matemáticos, ingenieros informáticos y especialistas en minería de datos (Sherer, 2012; Pérez Colomé, 2012; Peytibi, 2012). Simultáneamente, grupos más selectivos de simpatizantes fueron entrenados y dedicados a: 1) Verificar y aprobar los 'amigos' obtenidos en las cuentas de Obama en My Space y Facebook mediante análisis de preguntas y respuestas en los "posts" y 2) Aplicar test de eficiencia a distintos modelos de mensaje para solicitar dinero o colaboración mediante correos electrónicos.

La participación del ingente volumen de simpatizantes en estas tareas, en su mayor parte por el úni-

1 Diversos analistas consideran que Obama hubiera ganado de todos modos aquellas elecciones aunque todavía no hubiera existido internet. co motivo o recompensa de ayudar a su candidato, fue estimulada de una manera mucho más eficaz que la habitual involucración de militantes en tareas mecánicas y tediosas que las organizaciones políticas tradicionales suelen preparar. En su lugar, Dashboard aportaba un entorno de "gamificación"; como si fuera una especie de juego de mesa en el que cada participante desplegaba las habilidades de director de su propia campaña, en competencia con los restantes voluntarios de su barrio, distrito, estado o país. Un panel de datos informaba a cada integrante de sus logros semanales de actividad en comparación con las estadísticas del resto y el estímulo de esa competencia invitaba a redoblar esfuerzos. Por otra parte, la comunicación 'online' con los responsables de cada sección territorial fomentaba, no sólo el suministro 'hacia abajo' de sugerencias de actuación y materiales de apoyo, sino también la recepción 'hacia arriba' de iniciativas de los participantes. Como comentara Kreiss al respecto (2012: 27), "Ios simpatizantes necesitan sentir que sus contribuciones son valoradas para la buena marcha de la campaña, que sientan que se les escucha, porque de lo contrario no participarán". En realidad, la aparente discrecionalidad de los colaboradores caseros, que podría derivar en dispersión caótica, era sutilmente encauzada mediante una acción que Vaccari -ya en la campaña de 2008-, calificó con la metáfora del "pastoreo": al igual que ocurre con las ovejas aparentemente libres en mitad de un prado, los simpatizantes eran dirigidos hacia los objetivos buscados por la dirección de campaña, pero sin que parecieran imposiciones rígidas y apoyando las iniciativas personales que dicha dirección considerara aprovechables para el conjunto.

Con los datos masivos así obtenidos se acometía su microsegmentación, es decir, se trataba de detectar los más leves indicios de cambio en múltiples bolsas muy acotadas de electores (y no valoradas -por insignificancia estadística- en las encuestas tradicionales). Tras la detección de microperfiles novedosos y ajenos a las categorizaciones tradicionales se buscaba a continuación fomentar el acercamiento de los microgrupos de potencial oscilación, mediante el envío cuasi-personalizado de mensajes publicitarios selectivos (a través de Facebook y otras redes sociales). La información obte- 
nida mediante Google Analytics, compra de datos agregados de usuarios segmentados de Facebook y el cruce con otras bases comerciales permitía al equipo rector de la campaña una distribución muy minuciosa de su plan general de actuaciones. Como llegara a escribir un destacado comentarista, "la campaña no sólo sabía quién eras, sino exactamente cómo tenías que cambiar para convertirte en el tipo de persona que ellos querían que fueras" (Issenberg, 2012).

\section{AVANCES Y VARIACIONES EN LAS ELECCIONES USA DE 2016}

Al inicio de la carrera presidencial de 2016 todo indicaba que, a pesar de que el Partido Republicano había recortado bastante su retraso en la logística del análisis de datos, el Partido Demócrata estaría en mejores condiciones de aprovechar la acumulación de sus bases informatizadas y su experiencia en la gestión computacional. Y desde luego, así parecía confirmarse a medida que se perfilaba la primacía entre el electorado republicano del candidato que menos respaldo cosechaba de la cúpula institucional de su propio partido. Por esa impresión, cuando algunos periodistas preguntaron a Trump durante las primarias si no se consideraba en inferioridad en el terreno que mayor supremacía ostentaban los demócratas desde las victorias de Obama, este candidato contestó que consideraba "sobrevalorado" el papel de dicha herramienta en las campañas del anterior presidente (Lever, 2016). Acorde con ello, contrató para su dirección de actividad digital a un neófito en materia electoral, Brad Parscale, propietario de una pequeña empresa de márketing de San Antonio (Tejas). El propio Parscale declaró "haber pasado el proceso completo de primarias trabajando con un portátil en su sala de estar" (Andrews, 2016). Pero de sus escasos recursos, éste hizo virtud: Se concentró sólo en pequeños grupos susceptibles de cambiar su intención de voto o de abandonar la abstención en algunos estados clave. Analizaba reducidos puntos piloto y aplicaba sus resultados a muchos otros lugares de manera intuitiva. En muchas poblaciones el equipo de Trump ni siquiera tenía oficinas electorales (Tyson, 2016).
Cuando la carrera electoral entró en la confrontación final, dos circunstancias contrapuestas contribuyeron a disipar e incluso invertir el desequilibrio digital hasta entonces favorable, en apariencia, a la candidatura de Hillary Clinton. Respecto al campo de los demócratas había pasado desapercibido que en realidad no habían vuelto a contar con una herramienta de análisis y colaboración tan sofisticada como Dashboard, debido a que el alto coste de ese sistema, del que el Comité $\mathrm{Na}$ cional del partido aún seguía pagando las deudas contraídas, había obligado a desmantelarlo y a despedir a buena parte de los especialistas que lo habían gestionado (Kreiss, 2016, cap.6). Asimismo, la dura pugna sostenida durante las primarias entre los equipos digitales de Hillary Clinton y Bernie Sanders, con agrias disputas incluso por supuestos robos de datos entre ellos (Helderman et al., 2015), había desembocado en la desvinculación de parte de los apoyos que para actividades digitales hubiera recibido la ex senadora en condiciones normales. Por otra parte, aunque el equipo de logística y estrategia digital de Hillary Clinton, dirigido por reconocidos expertos como Jenna Lowenstein y Teddy Goff, dio la impresión de un espectacular rendimiento en las redes sociales (Dader, 2017: 65), en realidad demostró finalmente menor capacidad de afinar su incidencia en puntos clave, como en cambio logró el equipo de Trump.

Este último dispuso de una estructura digital por debajo de la mitad de su rival, con un coste mínimo en la mayor parte de la campaña y sólo desplegada a fondo en los dos meses finales. Pero precisamente, en agosto, tras obtener la designación como aspirante oficial republicano, el equipo de Trump invirtió intensivamente en logística digital y contrató la empresa Cambridge Analytica, cuyo éxito precedente más notorio había sido su trabajo a favor del Brexit del Reino Unido. Dicha empresa alardeaba en su página web (https:// cambridgeanalytica.org/) y en comparecencias públicas de su principal directivo Alexander Nix, de disponer de un modelo de microsegmentación psicográfica del electorado a partir de una pauta de combinación de más de cien variables, Ilamado OCEAN ("Openess, Conscientiousnes, Extraversion, Agreeableness, Neuroticism"). La elaboración de modelos psicográficos o de clasificación según "estilos de vida", en lugar de las estratificaciones 
sociodemográficas e ideológicas clásicas, tiene en realidad bastantes décadas de antigüedad en el campo académico y sus aplicación a los estudios de mercado. Pero mientras antes se podían basar tan sólo en encuestas de poco más de 1.000 entrevistados o en un escaso número de grupos de discusión, ahora tenían tras de sí ingentes agrupaciones de datos. Su elaboración partía de cuestionarios digitales aplicados a varios centenares de miles de voluntarios propietarios de páginas de Facebook, y con los criterios aportados por esta base decidieron concentrar su persuasión digital en pequeñas pero decisivas bolsas de votantes en estados clave. La eficacia de su estrategia quedó refrendada por los resultados electorales, ya que, al igual que en la campaña de Obama en 2012, pero esta vez con mayor dramatismo, el movimiento final de pequeños márgenes de voto arrancó a Hillary Clinton la victoria en delegados, quien sin embargo, había vencido en el cómputo global de los votos populares.

Trump, en efecto, obtuvo 2,8 millones de votos menos que Hillary Clinton (46,0\% frente al $48,1 \%$ de las papeletas), lo que ha supuesto la mayor desventaja en votos directos para un presidente electo en la historia de Estados Unidos. Pero en cambio Trump consiguió 306 delegados frente a los 232 de Hillary Clinton. Más en concreto, Trump ganó por 27.000 votos de 3 millones en Wisconsin; por menos de 2.000 de 4,5 millones en Michigan; por 68.000 de 6 millones en Pennsylvania, y por menos del 2\% en Florida (The New York Times, 4-12017). Sólo estos estados supusieron 75 delegados decisivos para la victoria del candidato republicano, gracias a estrechísimos márgenes que los estrategas digitales atribuían a su incidencia en las últimas semanas para conquistar votantes mediante mensajes específicamente orientados a sectores indecisos.

De todos es conocido el escándalo finalmente desatado respecto al procedimiento de obtención de los datos con el que, al parecer, la empresa Cambridge Analytica habría alimentado su sistema de microsegmentación y contactos cuasi-personalizados. Los cerca de 150.000 usuarios de Facebook estudiados para su modelo, además de responder a los cuestionarios aplicados habrían facilitado voluntariamente el acceso pleno a sus amigos en esa misma red, con sus corres- pondientes "muros" de actividad y demás datos sociodemográficos, pero sin el conocimiento ni permiso de estos. En total, unos 50 millones de internautas habrían aportado sin saberlo sus características y geolocalización. Lo cual habría servido, tanto para ampliar la consistencia interna del modelo psicográfico construido, como para para conectar después digitalmente con los sectores así perfilados, mediante mensajes adaptados a sus características.

Este tipo de explotación no autorizada de los datos de grandes masas de usuarios de Facebook no fue en realidad ninguna novedad, ya que Obama en 2012, mediante la instalación de un dispositivo llamado "Are you in?" en su página personal de Facebook, había capturado de la misma forma los contenidos expresados por todos los amigos de quienes entraban en el enclave de Obama y pulsaban el botón de esa herramienta. Dichos amigos no eran conscientes de que sus datos eran así transferidos al equipo de analistas de la campaña demócrata y, de esa forma, las conversaciones de sus muros, junto con sus datos biográficos, eran aprovechados para la preparación ulterior de contactos selectivos (Peytibi, 2012: 6). Pero, paradojas del impacto comunicativo, mientras la acción de los asesores de Trump ha supuesto un terremoto transnacional con graves consecuencias para las empresas implicadas, en el caso del equipo de Obama la acción no despertó el menor eco y nadie exigió cambios en la red social o responsabilidades de cualquier índole.

Más allá de tales diferencias en la percepción social de esas prácticas, el hecho es que la consultora contratada por Trump para los meses finales de gestión computacional de la campaña aplicó de manera intensiva, según sus propias declaraciones, una geolocalización digital de electores susceptibles de variar su inclinación a favor de Trump en los estados más igualados. Pero la actividad de las cibercampañas no se limita a lo que el equipo de trabajo interno de una candidatura sea capaz de investigar y desplegar sino que, en la comunicación global y multipolar que internet posibilita, las acciones de iniciativa autónoma de grupos colaterales de simpatizantes pueden tener un gran peso e incidencia. Si bien es cierto que esas intervenciones ajenas a la planificación del equipo central de campaña pue- 
den provocar "fuego amigo" y conducir al caos (como le sucedió al pionero digital Howard Dean en su campaña de 2004), en otras ocasiones pueden incrementar con mucho el alcance cibercomunicativo de una candidatura organizacionalmente débil. Y eso ocurrió sin duda en torno a Donald Trump: el discurso de este aspirante sintonizaba con la sensibilidad y actitudes de los difusos y heterogéneos grupos sociales de la "derecha alternativa" ("alt right"), de espíritu marginal e inicialmente desconectados de la vida política y las contiendas electorales, pero que vieron por primera vez a un candidato presidencial con el que identificarse. Muchos de ellos contaban ya con activas redes digitales, como la web Breitbart News (dirigida hasta poco antes de la elecciones por Stephen Bannon, el jefe de campaña de Trump); el bloguero Mike Cernovich, con 155.000 seguidores en Twitter, el creador de un comic de éxito, Scott Adams, con más de 100.000 seguidores entre Twitter y Periscope, y otra serie de supremacistas blancos y grupos antisistema de extrema derecha de intensa presencia e influencia en las redes sociales digitales (Pardo, 2016) Estos grupos actuaron por su cuenta -aunque como en el caso de Stephen Bannon algunos mantenían vínculos estrechos con el propio equipo del candidato- , y aplicaron lo que en el entorno de la plataformas españolas de Podemos en 2015-16 se ha llamado "el efecto de desborde"; es decir, que la actividad comunicativa de una organización política de pequeño alcance se vea positivamente superada por las colaboraciones de simpatizantes que realizan por iniciativa autónoma toda una serie de despliegues y contactos en beneficio de las ideas y aspiraciones de aquella organización política.

Finalmente, otro factor decisivo para la eficacia digital de Trump proviene de las características de su propio discurso, mucho mejor adaptado que el de su oponente al salto desde la comunicación de masas a la comunicación viral uno-a-uno, y al auge de la democracia sentimental y el emotivismo polarizante, que denuncia entre otros Arias Maldonado (2016).

Respecto a lo primero, resulta evidente que en el nuevo ecosistema de comunicación global los grandes medios de comunicación de masas no son ya los únicos instrumentos de difusión generalizada de los mensajes socioculturales o políticos. Esos medios resul- taban antes imprescindibles para llegar a la mayoría del electorado. Y para conquistar su atención y cobertura era preciso asumir su lógica discursiva y reglas de tratamiento, además de sus intereses económico-políticos, campos en los que sin duda se encontraba mucho mejor posicionada Hillary Clinton. La comunicación viral uno-a-uno permite en cambio saltarse el filtro mediático y llegar a la misma masa de potenciales votantes si se es capaz de activar con éxito los detonantes que determinan su eficiencia. Aquí no se trata de convencer a una élite de periodistas y empresas mediáticas de que el mensaje propuesto debiera ser verticalmente difundido desde sus plataformas sino de conseguir el contagio, persona a persona, mediante un mensaje de visibilidad minúscula en su origen, pero que por su alta capacidad de asombro, fuerza emotiva o choque perceptivo, provoque remultiplicación en cadena y el comportamiento de imitación gregaria ("irlo pasando"), incluso entre las propias élites mediáticas. Consiste en el fenómeno que el experto en marketing viral Antonio Núñez ha denominado "la estrategia del pingüino" (2016). ${ }^{2}$

Para ese propósito la estridencia declarativa de Trump se mostraba y se muestra especialmente dotada. Sus insultos, descalificaciones radicales o bravatas funcionan en las redes sociales como un imán, al que acuden tanto quienes se identifican con ellos, como quienes los rechazan e incluso quienes simplemente se asombran o se divierten con el espectáculo generado. Por esa atracción fueron también capturados los medios periodísticos tradicionales, que fueron incapaces de no mostrar y dejar de comentar los mensajes de Trump, convirtiéndose así en cooperantes involuntarios de su expansión masiva. Un dato muy significativo al respecto es que mientras Hillary Clinton y sus equipos de apoyo habían gastado a mediados de agosto de 2016 unos 103 millones de dólares en inserciones publicitarias en diferentes cadenas de radio y televisión, Trump no había invertido un solo dólar y sus simpatizantes apenas unos 12,4 millones (Morrow, 2016). Le bastaba con lanzar sus anuncios e imágenes en Twitter y esperar a que los grandes medios se hicieran eco de ellos, aunque fuera para criticarlos.

2 Cuando un pingüino se lanza al agua, todos los demás van detrás. 
Dicha estrategia de ataque zafio o descarnado plantea en principio un riesgo: que el volumen de los críticos supere de manera abrumadora al de los simpatizantes y éstos queden constreñidos a una minoría, como mucho significativa, pero incapaz de un victoria electoral. Ésta era sin duda la razón fundamental por lo que la mayoría de candidatos y partidos del sistema democrático tradicional evitaban asumir posturas muy radicales o controvertidas, convencidos por las evidencias de la sociología electoral de que las elecciones se ganaban con discursos 'de centro' o transversales y con vocación de "partidos atrapatodo" (cfr. Kirchheimer en Krouwel, 2003), de programas y lenguaje muy similar entre todos ellos, precisamente por su objetivo de conquista del espectro más amplio posible del arco ideológico. Frente a esa estrategia, situarse en los extremos radicales podía satisfacer la coherencia y autenticidad de algunas minorías, pero se consideraba un suicidio en materia de lucha electoral.

Tal enfoque no parece sin embargo tan necesario en los referidos tiempos de la "democracia sentimental". Bajo esta nueva atmósfera cultural, muchos ciudadanos reaccionan ante todo a lo que les emociona o impacta en sus afectos, y en ese terreno, las declaraciones calientes de quien muestra un lenguaje directo y "sin pelos en la lengua", recibe mucha más atención e incluso respeto que quien parece emplear un lenguaje frío, calculado e institucional (el típico del político profesional). Ese otro tipo de lenguaje se considera "sincero" y "auténtico" (aunque en términos racionales pudiera resultar disparatado), frente a la opresión del control social de "lo políticamente correcto". Así, puede verse incluso como una liberación del autoritarismo y otra forma de rebeldía "antisistema". El lenguaje agresivo y radical de personajes como Donald Trump contribuye a lo que también Arias Maldonado (2016) denomina un "emotivismo polarizante", mediante el cual los grupos sociales, en efecto, se tensan y distancian. Pero si la confrontación se generaliza, el electorado fragmentado que provoca puede permitir que una facción significativa se alce con la victoria, al no existir en frente ningún centro compacto y transversal.

El avance del multipartidismo a base de minorías radicalizadas en diferentes países refleja esa ten- dencia y en el caso de Estados Unidos el incremento sustancial de votantes a terceros candidatos -de 2,2 miIlones en 2012 a 7,8 en 2016, (Azhar, 2016) contribuyó a que desde un estridente y radicalizado discurso político, fomentado por la viralidad de las redes sociales, se pudiera llegar al poder. En esa efervescencia de los registros emocionales y los "debates incendiarios" en las redes sociales, las críticas vertidas por los medios periodísticos tradicionales sólo contribuyeron a visibilizar aún más al personaje. Tales medios fueron incluso desacreditados por Trump al despreciarlos como "parte del sistema", aprovechando así la corriente de anti-elitismo y anti-institucionalismo de cualquier signo ideológico. La ola de simpatía hacia quienes representan la "anti-política", también habitual en esta nueva sentimentalización de lo público, termina por afianzar a este tipo de agitadores de la opinión pública y ayuda a explicar el éxito de la campaña de Trump y el relevante papel jugado en ella por su cibercomunicación.

\section{LAS CIBERCAMPAÑAS ESPAÑOLAS DE 2015 Y 2016}

La incorporación a este nuevo estilo de campaña ha sido patente en los procesos electorales de carácter nacional desarrollados en España en 2015 y 2016, si bien la envergadura de nuestra gestión computacional y la explotación de sus estrategias asociadas quedan todavía a gran distancia de lo contemplado en el caso estadounidense.

Comenzando por el aspecto de los nuevos lenguajes ciberestridentes, orientados a la expansión viral, los líderes políticos españoles no han desplegado en las recientes campañas estilos discursivos tan radicalmente apelativos como el de Donald Trump, pero sí han explorado en algunos casos esa vertiente. Sin duda ha sobresalido en dicho aspecto el líder de Podemos, Pablo Iglesias, que, a partir de 2014, en buena medida irrumpió y se asentó en la vida pública española gracias al exhibicionismo -tanto en medios tradicionales como en redes sociales-, de una dialéctica de premeditada confrontación, desprecio de las posturas de consenso y gusto por las frases sorpresivas, destinadas al contagio viral. En la misma línea, aunque a otra escala, el líder de Izquier- 
da Unida, Alberto Garzón, consiguió en la campaña de 2015 una visibilidad muy superior a las expectativas de su formación mediante los mensajes irónicos y lúdicos que su equipo fue capaz de lanzar con gran éxito virtual. Destacó en ese sentido su campaña de los "gatetes": a partir de unos mensajes en los que el candidato aludía a los dos gatos domésticos de su hogar, se desató una oleada de simpatizantes de estos animales de compañía, que mostraban fotos de los suyos o respaldaban al candidato por esta afición común, mientras el propio político continuaba retroalimentado la comunicación con nuevas imágenes y mensajes acerca de sus mascotas. Su equipo generó la etiqueta \#GatetesConGarzón y consiguió con ella convertirse en tendencia principal durante varios días (Huffington Post, 2015, entre otros). Pero, sin duda, viene siendo el novel político independentista catalán Gabriel Rufián quien más recientemente, tanto en períodos electorales como fuera de ellos, ha prodigado los "tuits" más tremendistas para lograr de manera simultánea el protagonismo mediático y la diseminación viral de sus ataques discursivos. El escaso peso de este político en el arco parlamentario español queda superado con creces por su proyección mediática y digital, con lo que demostraría que el "estilo Trump" aporta unos réditos inimaginables en la ya de por sí espectacularizada pero más tradicional y anterior "Era de la Televisión". 3

Con carácter más general respecto a lo observado en España durante los dos procesos electorales de 2015 y 2016 (Dader y Campos (2017), la red social priorizada por nuestros partidos y candidatos fue Twitter, con publicaciones diarias en período de campaña de entre 30 y 200 mensajes por emisor. En ellos, el repertorio de 'etiquetas' o "hashtags" fue asimismo muy variado. La reunión de ambas características puede ser interpretada como síntoma de experimentación con un nuevo medio al que se supone muy influyente, pero sin que existiera una planificación muy clara. En cambio, y a diferencia de Estados Unidos, ni Twitter ni Facebook fueron aprovechados de manera relevante para la difusión de mensajes de coordinación logística, en los que se hi-

3 Para un interesante exposición del paralelismo en las estrategias discursivas en las redes sociales de Trump y Rufián, a partir del análisis de Georges Lakoff, véase, Villarreal, 2018. cieran propuestas al público general de participar en actividades o de colaborar en tareas de respaldo (cuestión ésta reservada a las redes internas de cada organización, pero sin explorar de manera habitual la apelación abierta al público general). Las retransmisiones de actos en directo y la inserción de vídeos en los 'posts' digitales fue otro recurso de creciente utilización.

Las organizaciones y líderes políticos españoles evidenciaron un gran afán por estar presentes en todo tipo de redes y plataformas. Pero lejos aún de un sistema integral 'online' que sincronice de manera efectiva la intervención en las múltiples plataformas. Y tampoco llegaron a enlazar de manera clara la comunicación digital con la mediática tradicional y el activismo comunitario de base ("offline"). Aun así, todos los partidos de gran implantación contaron con un departamento de gestión de la campaña digital y sus responsables respondían a perfiles profesionales muy diversos (entre periodistas, informáticos y diseñadores gráficos). Su gestión puede considerarse a mitad de camino entre la planificación y las reacciones intuitivas sobre la marcha. Todos los partidos reconocieron, a través de los responsables entrevistados en la indicada investigación, haber utilizado el análisis microsectorial de datos, pero con niveles diferentes 0 indeterminados de profundidad. Mediante contratación externa en su mayoría. En concreto, los representantes del Partido Popular (PP) y el Partido Socialista (PSOE) reconocieron haber dispuesto de algunos equipos de expertos propios, pero sin concretar demasiado la estructura o composición de los mismos. Asimismo, estos partidos reconocieron la preparación y explotación de algunas bases de datos internas: en el caso del PSOE, el archivo digital "Bloise", configurado desde varios años antes a partir de los datos sociodemográficos del Instituto Nacional de Estadística, que genera la segmentación en unas 36.000 secciones de todo el electorado español. En el caso del $P P$, el sistema informático de análisis de conglomerados temáticos "Calisto", que permite al partido agrupar de manera automática múltiples textos que sobre un tema particular estén circulando por internet en un momento determinado y generar una síntesis sobre el mismo (Redondo, Calvo, Díez Garrido, 2017). 
Entre las empresas de minería de datos que los diferentes partidos reconocieron haber contratado o que publicitan en sus webs trabajos electorales realizados para diversas formaciones figuran: Target Point (varios partidos en campañas nacionales y locales), Smartup (PSOE), Alto Data Analytics (Ciuadadanos y PP), Jim Messina Group (PP) y los servicios analíticos de Facebook (varios partidos). Algunas de esas empresas mencionan el empleo de herramientas informáticas de pago como Brandwatch, Audiense, Hashtagify y Social Mention. Recurren a ellas para análisis masivos de las conversaciones desarrolladas en las diferentes redes sociales, detectar las palabras más asociadas a ciertas cuentas o 'hashtags', identificar los usuarios o cuentas con potencial de influencia en un tema, etc. (Bejarano, 2017 y 2016).

En cuanto a actividades 'oscuras' o de "guerra sucia” en el activismo digital, también quedó patente el uso clandestino de 'robots' y activistas no identificados para acosar o desacreditar a adversarios. A este respecto, ningún entrevistado reconoció emplearlos pero acusaron a otros adversarios políticos de usarlos.

Para el conjunto de la gestión computacional desplegada en España en los procesos electorales indicados, las formaciones estudiadas declararon haber dispuesto de los siguientes equipos de trabajo y cooperación:

El $P P$, unas 3.000 personas "involucradas", más unos 2.500 militantes vinculados por Whatsapp y la emision de unos 80.000 mensajes de correo electrónico enviados mediante una lista de distribución durante el proceso electoral de diciembre de 2016.

El PSOE, un equipo universitario especializado en la gestión computacional y unos 15.000 voluntarios integrados en la red "Equipo del Cambio", para desarrollar diferentes tareas de análisis y activismo digital.

Ciudadanos, un equipo central y remunerado de 200 responsables de "anillos" de actividad digital, unos 1.400 voluntarios de segundo nivel, tres bases complementarias de contactos de entre $30.000 \mathrm{y}$ 100.000 simpatizantes y otros grupos de entre $600 \mathrm{y}$ 3.500 activistas conectados por Telegram.

Izquierda Unida, unos 20.000 simpatizantes movilizados a través de sus redes sociales, para apoyar las diversas iniciativas lanzadas por su pequeño equipo de estrategia digital.
En el caso de Podemos, el partido político que a los ojos de la ciudadanía y de los medios de comunicación, mayor despliegue digital viene desarrollando en el Estado español, curiosamente sus representantes entrevistados solo declararon haber contado con 15 personas actuando como "Equipo de Redes", más unos 10 miembros de la "Unidad de Comunicación" y unos equipos de apoyo de unas 200 personas para cada uno de los anteriores. No obstante, en el caso de este grupo y de sus diversas organizaciones satélites se ha venido reconociendo en otros trabajos académicos o divulgativos, el despliegue complementario, ya descrito en el entorno estadounidense, de iniciativas autónomas de grupos colaterales de simpatizantes que permiten a organizaciones de envergadura menor amplificar de manera muy eficiente la divulgación de sus idearios y valores. De esta manera, como de forma evidente sucedió en torno a Trump, los simpatizantes de Podemos y sus diversas candidaturas afines generaron por su cuenta mensajes e iniciativas de refuerzo que alcanzaban una difusión muy superior a la capacidad logística del núcleo dirigente, con la que al final igualaban o superaban el despliegue cibercomunicativo de los grandes partidos. Es lo que algunos participantes o expertos han llamado en España "acción multicapa" y "efecto de desborde" (Abell, 2016; Becares, 2015). Bajo esa estrategia, tanto en campaña electoral como fuera de ella, grupos de activistas cercanos a Podemos se han identificado como "Brigadas Moradas", dedicadas a realizar actuaciones de "guerrilla digital", tanto para rebatir en las redes sociales los mensajes de los adversaries externos, como incluso para los enfrentamientos internos entre los partidarios de sus diferentes líderes; como sucedió con los ataques sufridos por Íñigo Errejón cuando, posteriormente a los referidos procesos electorales, disputó el liderazgo a Pablo Iglesias (Gil, 2017; ElDiario.es, 2016).

Por otra parte, lo declarado por los entrevistados de los partidos políticos es muy probable que quede bastante por debajo de la infraestructura y modalidades de activisimo digital realmente desplegados por algunas de esas organizaciones. Así lo hace suponer, por ejemplo, la revelación anónima obtenida en la indicada investigación dirigida por Dader y Campos (2017) sobre uno de los partidos analizados: bastante por encima de 
lo declarado por sus representantes, contaron con un núcleo de 600 militantes de dedicación intensiva coordinados por Whatsapp (para distribuir los argumentarios y directrices elaborados por un pequeño equipo rector), además de unos 20.000 simpatizantes/voluntarios para ejecutar acciones digitales, incluyendo 'trabajo sucio' en las redes (como alimentación de 'bots' con mensajes no atribuibles al partido, etc.).

Entre las acciones de gestión computacional de datos que sí dejaron constancia pública en la campaña electoral de 2016 destaca sin duda la desarrollada por la empresa estadounidense de Jim Messina para el Partido Popular: Consistió en la detección entre los usuarios de Facebook de bolsas específicas de votantes indecisos en circunscripciones con escaños muy reñidos para, a continuación, enviarles a través de la misma red social publicidad electoral adaptada a sus perfiles. Para elaborar esos mensajes aplicaban también pruebas 'online' de eficiencia de mensajes destinados al correo directo y a textos entregados puerta a puerta. Según algunas informaciones publicadas (Mucha y Negre, 2016), se le atribuye a esta intervención no sólo parte de la mejora de los resultados finales del $P P$ con respecto a los previstos al inicio de la campaña, sino también haber vaticinado un número de escaños casi idéntico al obtenido, frente al error general de los pronósticos de los sondeos electorales.

La gestión computacional de una parte de la campaña electoral se ha instaurado, en definitiva, como un componente de relevancia creciente en la estrategia y la logística desplegadas por los grupos políticos en España. Y todo apunta a que su protagonismo tenderá a crecer en las siguientes convocatorias a urnas (Gil, 2018; Sela 2018).

\section{UN CAMBIO DE PARADIGMA EN LA CONCEPCIÓN DE LAS CAMPAÑAS}

Ya en el año 2012 algunos responsables de tareas digitales del equipo de Obama declaraban (Pérez Colomé, 2012) que en su nueva forma de afrontar el proceso electoral "la política da igual", en el sentido de que ahora importan menos los errores políticos o los temas de discusión si se consigue transmitir de manera directa a un número suficiente y personalizado de electores las razones concretas para votar al candidato. Por ello, el objetivo se desplaza del dominio de los grandes medios de comunicación al contacto particular y directo con el volumen más amplio posible de ciudadanos a los que se sea capaz de movilizar. Los medios periodísticos pueden estar realizando una severa crítica al líder político o a su partido, pero la influencia mediática puede quedar orillada y contra argumentada por los contactos directos que el equipo electoral y sus intermediarios digitales consigan establecer con cientos de miles o millones de individuales votantes potenciales. Por eso también, un organizador de base local de ese mismo equipo añadía que "veo las campañas como construir una lista".

El objeto de deseo más preciado se desplaza, en definitiva, de las buenas relaciones con el sistema mediático al registro minucioso de las más extensos repertorios de direcciones digitales geolocalizadas. Para, a partir de ello, desplegar una comunicación reticularmente personalizada ejerciendo lo que algunos Ilaman el "two-step-flow digital" (Bimber, 2014:139; Vaccari, 2013: 199); esto es, que el mensaje recibido por el elector individual, no sea el diseñado de manera genérica por el candidato y su equipo, para la difusión de masas; sino el que le llega a aquél, a través de un amigo o una persona de su entorno y que, en lugar de ofrecerle eslóganes o consignas genéricas, utiliza argumentos mucho más cercanos y sensibles a las preocupaciones inmediatas de ese elector final. En palabras de Sara Vissers (2009: 27), ahora se trata de que las campañas no se limiten a "predicar a los evangelizables" sino "a través de los conversos".

Tal cambio en la articulación nuclear de las campañas conlleva plantearse si, en cierta forma, el estilo de electoralismo de masas que ha dominado durante casi un siglo en las democracias industrializadas y urbanas, podría estar retornando, mediante nuevas herramientas, a un estilo más propio del mundo rural y las comunidades pequeñas, en el que los grandes medios de comunicación de masas no habían hecho acto de presencia o carecían de poder de influencia. Justamente en el momento en que las experiencias descritas muestran la eclosión en su máxima expresión de la "tecnopolítica" (Lebkowsky, 1997; Rodotà, 1997; Kur- 
ban et al. 2016), podríamos estar ante el surgimiento de lo que en otros trabajos personalmente he denominado el "tecnocabildeo" (Dader, 2017).

La palabra "cabildo", de vieja tradición en el español pero de uso muy restringido en la actualidad, se define en diversos diccionarios como "corporación o grupo de personas integrado por un alcalde y varios concejales que se encarga de administrar y gobernar un municipio." Y también puede referirse a toda agrupación pequeña de personas que constituyen un grupo cerrado o compacto (como 'el cabildo de los sacerdotes de una catedral', etc.), o conjunto de miembros de una corporación o gremio que se ayuden o socorren mutuamente. Resulta análoga, por tanto, a pequeña comunidad o "cofradía".

El término cabildo suele asociarse también de manera intuitiva con la relación "clientelar" que se produce dentro de un pequeño grupo, entre el jefe o líder principal del mismo y los restantes miembros de esa corporación, que tienden a depender de las órdenes 0 peticiones del primero. En esa misma línea, en ciencia política se entiende por clientelismo, la actividad desarrollada por ciertos gobernantes o por quienes ocupan una posición de poder, consistente en otorgar ciertos beneficios a otras personas a cambio de favores, apoyo 0 sumisión. Por esa razón, se puede considerar de manera coloquial como cabildear, la actividad del líder o jefe de una pequeña comunidad para asegurarse el respaldo de los miembros de la citada comunidad mediante la promesa de beneficios particulares o la amenaza de represalias, en caso de que los subordinados no acepten las peticiones del líder (como por ejemplo, pedirle que le voten en unas elecciones a cambio de puestos de trabajo, permisos de edificación, supresión de sanciones, etc.). En concreto, el Diccionario de la Real Academia Española define cabildear como: "hacer gestiones con actividad y maña para ganar voluntades en un cuerpo colegiado o corporación".

En ese sentido, la figura del jefe del cabildo resulta equivalente a la del cacique o jefe local, que controla de manera autoritaria una comunidad y que en el caso de celebrarse elecciones conoce a cada uno de los miembros de su comunidad (o a muchos de ellos) y puede prometer cosas concretas o amenazar con re- percusiones específicas a cada elector para conseguir sus votos. En sociología política, la actividad del cabildeo o clientelismo ha estado vinculada históricamente al control ejercido por caciques locales o líderes autoritarios de pequeñas comunidades que se aseguraban la victoria electoral en su distrito mediante ese contacto directo con los electores y ese empleo de los favores y amenazas para asegurarse sus votos. En tales contextos la campaña electoral, los discursos de los candidatos y la publicidad política carecen de importancia, ya que el líder se asegura la victoria por la vía de la contraprestación de intereses y no por la de la seducción de la imagen o la propaganda.

Se supone que en las sociedades democráticas desarrolladas, el ejercicio del cabildeo y el clientelismo electoral fueron perdiendo importancia a medida que las relaciones interpersonales estaban mucho más masificadas y los líderes no podían conocer ni contactar uno a uno con los millones de votantes, ni menos aún prometerles o amenazarles con cosas concretas a cada uno de ellos. Por eso las campañas electorales en las sociedades de masas pasaron a ser de emisión masiva de publicidad y de mensajes persuasivos genéricos, destinados a seducir de manera simultánea a millones de personas anónimas y atomizadas.

Sin embargo, en el seno de las propias sociedades de masas, se mantienen algunas modalidades de procesos electorales de pequeña comunidad o cabildo, en las que el conocimiento recíproco entre los miembros de esa "cofradía" puede hacer más rentable las prácticas clientelares y el contacto interpersonal, en lugar de las acciones de propaganda y publicidad de masas. Se trata de los comicios municipales en poblaciones muy pequeñas, o las elecciones dentro de un colegio profesional o agrupaciones de escasa envergadura, como una Facultad universitaria, una asociación de vecinos, etc. En estos casos, tener la lista de los miembros del colectivo y poder hablar con cada uno de ellos para "negociar" su voto, a cambio de promesas particulares, es mucho más importante que los slogans de campaña, las declaraciones y discursos generales o los programas electorales.

Si hasta ahora las campañas electorales de los países democráticos venían respondiendo a la lógica de 
la persuasión masiva a través de los grandes medios de comunicación (televisión, radio, prensa, publicidad...), las nuevas herramientas de la comunicación online abren la posibilidad de que esas campañas para conquistar el voto de millones de personas puedan aplicar la lógica de las comunidades pequeñas y el contacto persona a persona, facilitando el cabildeo o clientelismo mediante los medios tecnológicos de la capilaridad virtual.

Si conforme a la lógica clientelar la negociación de contraprestaciones resulta más pertinente que la persuasión de masas indiferenciada, el nuevo estilo de campañas hiper-personalizadas que descubre el activismo digital orquestado para las intervenciones "multicapa" y de "desborde" puede hacer que, como mínimo, coexistan y sean necesarios a partir de ahora dos modelos de electoralismo comunicativo: el tradicional y el "tecnocabildeado". Este último se percibe ya, como he escrito en otro lugar (Dader et al. 2017: 441-442), "cuando los errores de bulto, denuncias o duras críticas sufridas en las plataformas mediáticas se pueden compensar después con las modulaciones y reorientaciones que los simpatizantes bien sincronizados en una "guerrilla cibernética" pueden estar susurrando al oído de una escalonada cadena de decenas de miles de contactos; para que a su vez éstos los trasladen a sus respectivos ámbitos de comunicación interpersonal con los electores finales".

Cabe pensar, sin embargo, que el 'tecnocabildeo', facilitado mediante listados informáticos hipersegmentados, y ejercido mediante un fluido contacto directo, quizá no alcanzará nunca en sociedades con alta protección de datos y menores infraestructuras para la minería de los mismos, el nivel de detalle y capilaridad que las últimas campañas estadounidenses han mostrado. Asimismo, incluso en ese país, el mensaje personalizado que el activismo digital ofrece quizá no se aproxime nunca al nivel de contraprestaciones interesadas que tradicionalmente han manejado los clásicos caciques locales de la política. A ese respecto, Daniel Kreiss percibe también el paralelismo de las estrategias digitales con las formas clientelares de la política decimonónica, pero considera impensable su recuperación literal. Pero aun así manifiesta: "Mientras el clientelismo ("patronage") es esencialmente una cosa del pasado, al me- nos en Estados Unidos, la idea de aprovechar el conocimiento de la totalidad de los ciudadanos [al estilo de los políticos del XIX que recorrían su distrito y visitaban cada hogar para conocer sus circunstancias particulares], sus necesidades, aversiones, problemas y esperanzas aprovechando estratégicamente ese conocimiento con fines electorales, resulta evocador en nuestro propio tiempo." (Kreiss, 2016: e-book, posición 5023).

La campaña 'online' total ya consignada en 2012 en Estados Unidos (Pérez Colomé, Moceri, Peytibi et al 2012), y confirmada en 2016, con evidentes signos de aproximación en otros países como España, nos aboca en definitiva a un cambio de paradigma en la construcción global de la estrategia electoral de los partidos y candidatos de las democracias tecnológicamente avanzadas. La tecnopolítica actual no se limita ya a un adorno escénico o un amplificador de los impactos generados por vías más tradicionales (como pudiera ser el caso del uso de hologramas, sitios web, etc.), sino que alcanza también un cambio radical en la manera de estructurar el proceso comunicativo global entre dirigentes y ciudadanos de a pie.

Durante décadas, los defensores del ideal democrático de una comunicación política plural, igualitaria, transparente y argumentada han criticado amargamente la alienación ciudadana provocada por el simplismo y banalización de la realidad política ejercidos en las campañas mediatizadas masivas. Pero no está claro que las novedosas orientaciones que facultan las herramientas de la comunicación digital vayan a sustituir ese viejo sistema de imágenes políticas estereotipadas por una nueva arena pública de deliberación y contraste más rigurosos. De entrada, las prácticas de rastreo e interrelación de datos plantean inquietantes dudas respecto a los límites de la privacidad y el derecho de los ciudadanos a mantenerse alejados de las presiones propagandísticas de las organizaciones políticas. A lo anterior se añade el temor de nuevas desigualdades antidemocráticas entre los grupos que compiten en elecciones con muy dispares equipamientos en la logística digital. Y en último término, surge la amenaza de que la propaganda de masas sea sustituida, al menos en parte, por una especie de clientelismo de masas, escalonado mediante ejércitos de activistas digitales, 
capaces de anular el contrapeso crítico que, al menos en parte, proporcionaban los medios periodísticos más comprometidos con el ideal del "perro guardián" democrático.

Pero más allá de las evaluaciones dispares que quepa hacer de este cambio de paradigma, el hecho innegable es que la cibercomunicación y la gestión computacional de campañas se han instalado ya en los procesos electorales y han transformado su escenario de una manera irreversible. ।

\section{REFERENCIAS}

» ABELL, Catalina (2016): "Las redes del cambio. Análisis sobre el uso de las redes sociales y las TIC por parte de la candidatura municipal Ahora Madrid en las elecciones municipales de 2015". Trabajo Fin de Máster. Máster en Estudios Avanzados de Comunicación Política. Facultad de Ciencias de la Información. Madrid: Universidad Complutense.

» ANDREWS, Nathalie (2016): "How the Trump Campaign (Eventually) Embraced Data", The Wall Street Journal, 14 de diciembre, http://blogs.wsj.com/washwire/2016/12/14/how- the-trump-campaign-eventually-embraced-data/ [último acceso 29 de diciembre, 2016].

» ARIAS MALDONADO, Manuel (2016): La democracia sentimental. Barcelona. Página Indómita.

» AZHAR, Hamdan (2016): "2016 vs. 2012: How Trump's Win and Clinton's Votes Stack Up to Romney and Obama", Forbes.com, 29 de diciembre. www.forbes. com/sites/realspin/2016/12/29/2016vs-2012-how-trumps-win-and-clintons- votes-stack-up-to-obama-and-romney/\#2acc18047033 [último acceso 30 de diciembre, 2016].

» BECARES, Roberto (2015): El efecto Carmena. Madrid. Libros.com

» BEJARANO, Carolina (2017): "Segmentación política estratégica en la era de Internet", La Revista de ACOP, no 16, pp. 5-13.
» BEJARANO, Carolina (2016): "El marketing digital de las empresas de comunicación política: estrategias y técnicas para las nuevas campañas 'online' en España". Trabajo Fin de Máster. Máster en Estudios Avanzados de Comunicación Política. Facultad de Ciencias de la Información. Madrid: Universidad Complutense.

» BIMBER, Bruces (2014): “Digital Media in the Obama Campaigns of 2008 and 2012: Adaptation to the Personalized Political Communication Environment", Journal of Information Technology \& Politics, vol. 11: 2, pp. 130-150.

» COTARELO, Ramón (2013): Ciberpolítica: Las nuevas formas de acción y comunicación políticas. Valencia. Tirant lo Blanch.

» COTARELO, Ramón / GIL, Javier (eds.) (2017): Ciberpolítica. Hacia la cosmópolis de la información y la comunicación. Madrid. Instituto Nacional de Administración Pública.

» DADER, José Luis (2017): “Campañas políticas 'online': La realidad española frente al horizonte internacional del 'tecnocabildeo'”, pp. 11-73, en DADER, José Luis / CAMPOS, Eva (eds.) Op. Cit.

» DADER, José Luis / CAMPOS, Eva (eds.) (2017): La búsqueda digital del voto. Cibercampañas electorales en España 201516. Valencia. Tirant Lo Blanch / ALICE.
» DAVIS, Richard (1999): The Web of Politics. The Internet's Impact on the American Political System. New York. Oxford University Press.

» ELDIARIO.ES (2016): "Los afines a Pablo Iglesias lanzan la campaña \#íñigoAsíNo contra Errejón", El Diario.es, 24 de diciembre, www.eldiario.es/rastreador/ campana-InigoAsiNo- Errejon-dividir-Podemos_6_594300569.html [Último acceso 26 de abril, 2018].

» EL HUFFINGTON POST (2015): "Alberto Garzón arrasa en Twitter con sus gatos", 5 de diciembre, www.huffingtonpost.es/2015/12/05/garzon-gatos-twitter_n_8728328.html [Último acceso 30 de abril de 2018].

» GIL, Iván (2018): "Podemos organizará un ejército de activistas en redes sociales para las elecciones de 2019", El Confidencial, 2 de marzo, www.elconfidencial. com/espana/2018- 03-02/podemos-campana-electoral-activistas-redes-sociales_1529388/ [Último acceso, 30 de abril, 2018].

» GIL, Iván (2017): “De la 'guerrilla' ciberactivista a las 'brigadas moradas': así manda Podemos en las redes", El Confidencial, 7 de marzo, www.elconfidencial. com/espana/2017-03-07/guerrilla-brigadas-moradas-podemos-redes- sociales_1343312/ [Último acceso 26 de abril, 2018]. 
» HELDERMAN, Rosalind / GEARAN, Anne / Wagner, John (2015): "DNC Penalizes Sanders Campaign for Improper Access of Clinton Voter Date", The Washington Post, https://www. washingtonpost.com/politics/dnc-sanders-campaign-improperly-accessed-clinton-voter-data/2015/12/17/ a 2 e 2 e 14 e - a 522 - 11 e 5 - b 53 d $972 \mathrm{e} 2751 \mathrm{f} 433$ story.html?utm_term=. e372a532bd72 18-Diciembre [último acceso 15 de marzo de 2017].

» HILL, Kevin / HUGHES, John (1998): Cyberpolitics: Citizen Activism in the Age of Internet. Lanham, MD. Rowman and Littlefield.

» ISSENBERG, Sasha (2012): "How President Obama's Campaign Used Big Data to Rally Individual Voters", Mit Technology Review, 19 de diciembre, www.technologyreview.com/featuredstory/509026/ how-obamasteam-used-big-data-to- raIly-voters/ [Último acceso 14 de mayo, 2016].

» KREISS, Daniel (2016): Prototype Politics. Tecnhology-Intensive Campaigning and The Data of Democracy. New York: Oxford University Press.

» KREISS, Daniel (2012): Taking Our Country Back: The Crafting of Networked Politics from Howard Dean to Barack Obama. New York: Oxford University Press.

» KROUWEL, André (2003): "Otto Kirchheimer and the catch-all party", West European Politics, 26: 2, pp. 23-40, http://dx.doi. org/10.1080/01402380512331341091

» KURBAN, Can / PEÑA-LÓPEZ, Ismael / HABERER, María (2016): "What is Technopolitics: A Conceptual Scheme for Understanding Politics in the Digital Age", pp. 499-519, en BALCELLS, Joan et al. (eds.), Building a European Digital Space. Barcelona. UOC/ Huygens.

» LaPOTIN, Kathryn (2008): The Age of Cyberpolitics: Internet Campaigning in a Modern, Youth-Friendly World. Digital Research Archive, https://auislandora.wrlc.org/islandora/object/0708capstones:230 [Último acceso, 23 de abril, 2018].

» LEBKOWSKY, Jon (1997): "TechnoPolitics". En 21C, Melbourne. The Commission. 11 de enero.

» LEVER, Rod (2016): "Big Data Helped Trump Even after He Scorned It", Phys. org, 4 de diciembre, http://phys.org/ news/2016-12-big-trump-scorned.html [Último acceso 30 de diciembre, 2016].

» MARTINS, Constantino Pereira (2013): "What is Cyberpolitics?", Lisboa. Universidade Nova de Lisboa, www.academia edu/7554424/What is Cyberpolitics [último acceso 21 de abril, 2018]

» MOCERI, Alana (2012): "Elección 2012 de EEUU: ¡Son los datos, estúpido!”, El Molinillo [Revista de ACOP]. No 48, pp. 8-11.

» MORROW, Brendan (2016): "How Much Money Have Hillary Clinton \& Donald Trump Spent on Campaign Ads?", Heavy.com. Agosto. https://heavy.com/ news/2016/08/hillary- clinton-donaldtrump-how-much-has-have-spent-oncampaign-advertising-ads- commercials-spending-groups-money-august/ [último acceso 29 de abril, 2018]

» MUCHA, Martín/NEGRE, Javier (2016): "La gurú de San Francisco que hizo ganar las elecciones a Mariano Rajoy", El Mundo, 3 de julio, www.elmundo. es/cronica/2016/07/03/57779fc0ca4741301d8b4609.html [último acceso 26 de julio, 2016].

» NúÑEZ, Antonio (2011): La estrategia del pingüino. Influir con mensajes que se contagian de persona a persona. Barcelona. Mondadori.

» PARDO, Pablo (2016): "La 'neoderecha': misóginos, trolls y xenófobos", El Mundo, 10.Noviembre, www.elmundo.es/ internacional/2016/11/10/58227e03e5fdea4a668b464d.html [último acceso, 27 de abril, 2018].

» PÉREZ COLOMÉ, Jordi (2012): "La campaña de base de Obama", El Molinillo [Revista de ACOP]. No 48, pp. 12-15.

» PEYTIBI, Xavier (2012): "USA 2012, la campaña online", El Molinillo [Revista de ACOP], No. 48, pp. 4-7.

» REDONDO, Marta / CALVO, Dafne / DÍEZ GARRIDO, María (2017): "Calisto, un software para la construcción del discurso político". El profesional de la información. 26 (4) pp. 756 - 764.

» RODOTÀ, Stefano (1997): Tecnopolitica. La democrazia e le nuove tecnologie deIla comunicazione. Roma: Laterza.

» SELA, Luz (2018): "El Nuevo Govern prevé un ejército de voluntarios en las redes sociales para replicar al Ejecutivo", OKDiario, 11 de marzo, https://okdiario.com/espana/2018/03/11/nuevo-go- vern-preve-ejercito-voluntarios-redes- sociales-replicar-ejecutivo-1941499 [Último acceso, 30 de abril de 2018].

» SHERER, Michael (2012): "Inside the Secret World of Data Crunchers Who Helped Obama Win", Time, 7-Nov, http:// swampland time.com/2012/11/07/inside-the-secret- world-of-quants-and-datacrunchers-who-helped-obama-win/ [último acceso, 16 de febrero, 2018].

» THE NEW YORK TIMES (2017): "Presidential Election Results: Donald J. Trump Wins", The New York Times, 4 de enero, http://www.nytimes.com/elections/ results/president [Último acceso 11 de enero, 2017]

» TYSON, Matthew (2016): "How Digital Marketing Helped Donald Trump Win", The Huffington Post, 19 de diciembre, www.huffingtonpost.com/matthew-tyson/how-digital- marketing-heI b 13721224.html [Último acceso 28 de diciembre, 2016].

» VACCARI, Christian (2013): Digital Politics in Western Democracies. A Comparative Study. Baltimore (Maryland): John Hopkins University Press.

» VACCARI, Christian (2010): “'Technology Is a Commodity': The Internet in the 2008 United States Presidential Election", Journal of Information Technology \& Politics, vol. 7, pp. 318-339.

» VILLARREAL, Antonio (2018): "Trumpo o Rufián 'controlan tu mente' con sus tuits: Evítalo con estos consejos de Lakoff", El Confidencial, 28 de enero, https://www.elconfidencial.com/tecnologia/2018-01-27/lakoff-ensena-manejar-populista- twitter_1511909/ [Último acceso, 30 de abril, 2018].

» VISSERS, Sara (2009): "From Preaching to the Converters to Preaching through the Converted", Comunicación en el ECPR Workshops. Lisboa: ISCT Lisbon Institute. 14 al 19 de abril. 